\title{
The preparation of highly substituted pyridazines via a tethered imine-enamine (TIE) procedure
}

\author{
Peter H. Geyelin, Steven A. Raw, and Richard J. K. Taylor* ${ }^{\dagger}$ \\ Department of Chemistry, University of York, Heslington, York, YO10 5DD, UK \\ E-mail:rjkt1@york.ac.uk
}

\begin{abstract}
1,2,4,5-Tetrazines can be converted directly into cyclo-annelated pyridazines via an inverse electron demand Diels-Alder procedure incorporating tethered imine-enamine (TIE) methodology. This methodology provides an improved one-pot preparation of such compounds, eliminating the need for either the preformation of the enamine or a separate aromatisation step, and has been applied to 4 tetrazines producing 11 pyridazines.
\end{abstract}

Keywords: 1,2,4,5-Tetrazines, pyridazines, inverse electron demand Diels-Alder

\section{Introduction}

The inverse electron demand Diels-Alder reaction of 1,2,4-triazines $\mathbf{1}$ with enamines $\mathbf{2}$ has been previously utilised to prepare a range of substituted pyridines 5 (Scheme 1). ${ }^{1-5}$ This procedure was greatly improved by Boger et al. who developed modifications which enabled the enamine $\mathbf{2}$ to be prepared in situ. ${ }^{2}$ With more substituted examples, however, the final elimination/aromatisation step of intermediate $\mathbf{4}$ can prove problematic and a separate oxidation/Cope elimination may be required to complete the sequence. ${ }^{2 b, 3,4}$

To overcome this problem, we developed the tethered-imine-enamine (TIE) procedure shown in Scheme 2. ${ }^{4}$ Thus, $N$-methylethylenediamine on treatment with two equivalents of a ketone in situ produces imine-enamine 7 which, after reaction with 1,2,4-triazine $\mathbf{1}$ and subsequent retro-Diels-Alder reaction, generates the tethered imine 8a. We envisage the imine acting as a tethered base to facilitate conversion into the corresponding pyridine $\mathbf{5}$ by promoting an E1cb mechanism or epimerising adjacent to the amine leaving group to enable an antielimination to take place. We also conjectured that the zwitterionic species $\mathbf{8} \mathbf{a}^{\prime}$ could be present to some extent thus enhancing the basic nature of the tethered imine (and mimicking the $N$-oxide intermediate in the Cope elimination).

${ }^{\dagger}$ Richard Taylor was Chairman of the RSC Heterocyclic Group during the period 1999-2001 


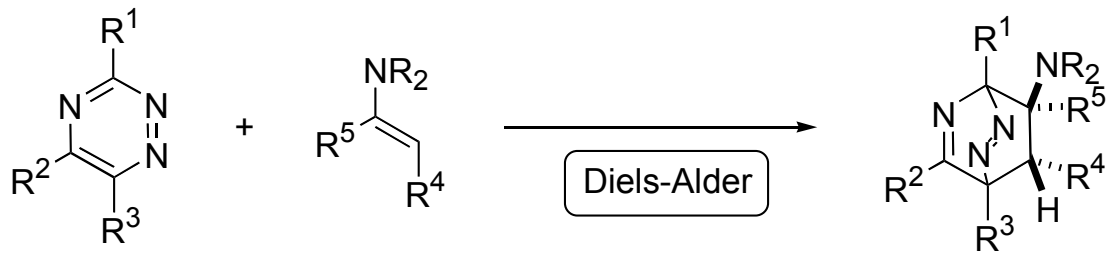

1

2

3

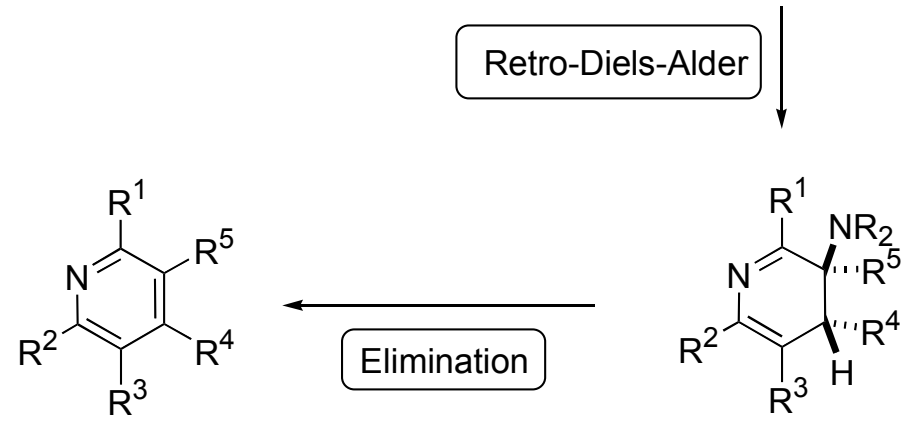

5

4

\section{Scheme 1}
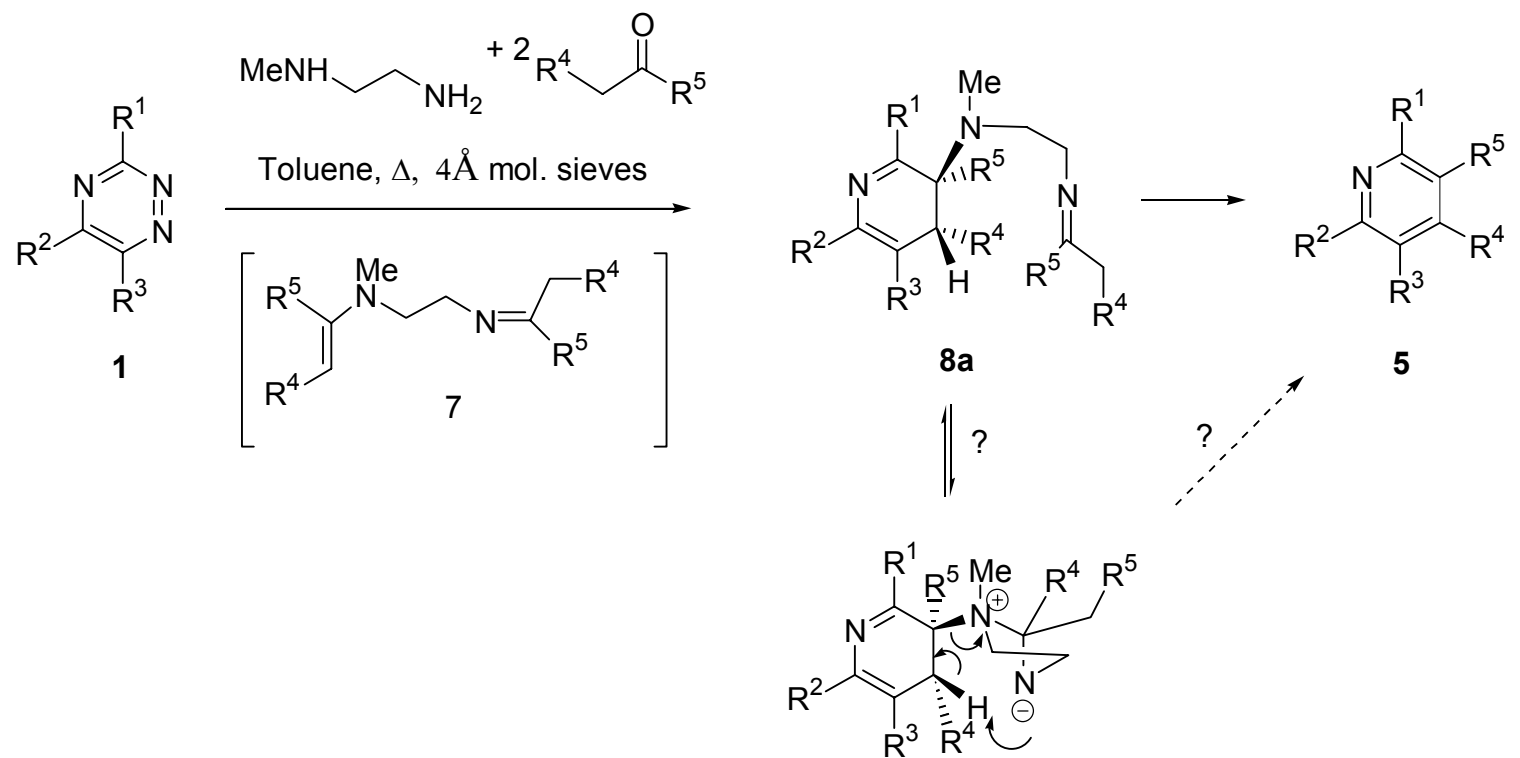

$8 a^{\prime}$

\section{Scheme 2}

Whatever the validity of the mechanistic speculation shown in Scheme 2, the TIE procedure was successfully utilised to prepare a wide range tri-, tetra- and penta-substituted 
pyridines 5 in high yields. ${ }^{4}$ In this paper, we report on the extension of the TIE procedure to the preparation of pyridazines from substituted-1,2,4,5-tetrazines.

\section{Results and Discussion}

Inverse electron demand Diels-Alder reactions of 3,6-disubstituted-1,2,4,5-tetrazines have received considerable attention, ${ }^{1,5}$ although reactions with enamines derived from cycloalkanones, leading to pyridazines have been less well explored. ${ }^{5 b, 5 c, 5 \mathrm{~h}}$ In order to evaluate the usefulness of the TIE methodology in this area, our first objective was to compare the TIE methodology with standard Boger in situ enamine procedure (Scheme 3). Thus, when the onepot reaction of commercially available diphenyltetrazine 9 with the enamine formed from cyclohexanone and pyrrolidine was carried out, the non-aromatised adduct $\mathbf{1 0}$ was obtained as the sole product in $69 \%$ yield. Application of the TIE procedure, that is treatment of tetrazine 9 with $\mathrm{N}$-methylethylenediamine and two equivalents of cyclohexanone, resulted in the direct formation of pyridizine 11, in a yield of $85 \%$ (Scheme 3). Further optimisation studies indicated that the molecular sieves were not required and that the use of an excess of $N$ methylethylenediamine ( 3 equiv.) and ketone (6 equiv.) sometimes gave improved yields - -these conditions were therefore adopted as standard.
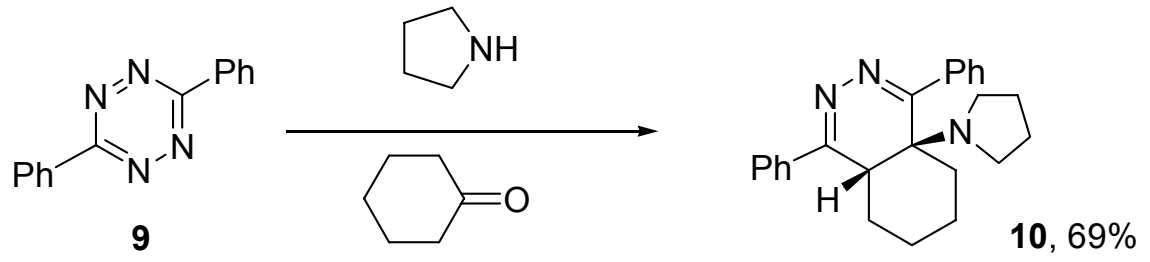

$\mathrm{CHCl}_{3}$, mol. sieves, $\Delta, 20 \mathrm{~h}$

$69 \%$<smiles>c1ccc(-c2nnc(-c3ccccc3)nn2)cc1</smiles>

9

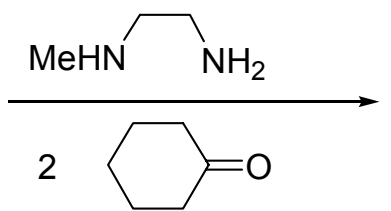

$\mathrm{CHCl}_{3}$ or $\mathrm{PhMe}$

mol. sieves, $\Delta$<smiles>c1ccc(-c2nnc(-c3ccccc3)c3c2CCCC3)cc1</smiles>

$\mathrm{CHCl}_{3}, 20 \mathrm{~h}, 85 \%$

PhMe, 13 h, 85\%

\section{Scheme 3}

Having successfully prepared pyridazine $\mathbf{1 1}$ in a one-step procedure, and having once again demonstrated the efficiency of the TIE procedure in the aromatisation step, we went on to explore the scope of the reaction with respect to the ketone (Table 1). It was established that tetrazine 9 reacts efficiently with a range of cyclic ketones from cyclopentanone to 
cyclooctanone giving the corresponding pyridazines 11-14 in high yields (85-97\%, entries i-iv)

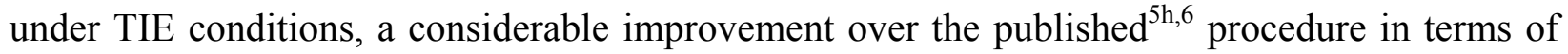
both operational simplicity and yields. Tetrazine 9 also underwent reaction with 3-coumaranone to give pyridazine $\mathbf{1 5}$ in $95 \%$ yield by a one-pot process (entry v): the reported ${ }^{5 \mathrm{c}}$ procedure for the preparation of $\mathbf{1 5}$, not only requires preformation of the enamine (derived from pyrrolidine and 3-coumaranone), but also requires a second aromatisation step, giving $\mathbf{1 5}$ in a $60 \%$ overall yield.

Table 1. Reactions of 3,6-diphenyl-1,2,4,5-tetrazine (9) with ketones (6.0 equiv.) and Nmethylethylenediamine (3.0 equiv.) in refluxing toluene

Entry

Having successfully demonstrated the TIE procedure to be an improved method for the direct conversion of tetrazine 9 into highly substituted pyridazines, we went on to explore the scope of the reaction in terms of the tetrazine (Table 2). Atfah has reported the reaction of commercially available 3,6-di-2-pyridyl-1,2,4,5-tetrazine (16) with the enamines derived from cyclohexanone, cycloheptanone and cycloctanone but utilising a three-step synthesis (enamine 
formation, cycloaddition and aromatisation). ${ }^{5 \mathrm{~h}}$ The requirement for a discrete aromatisation step provided an opportunity to apply our TIE procedure to this more challenging substrate. As can be seen (entries i-iii), pyridazines 17-19 were obtained in yields of $41 \%, 71 \%$ and $30 \%$, respectively, via the one-pot process using refluxing xylene as solvent (the yields in toluene were considerably lower). The reaction of tetrazine $\mathbf{1 6}$ with cyclopentanone and $\mathrm{N}$ methylethylenediamine, failed to give corresponding pyridazine product.

Table 2. Reactions of tetrazines with carbonyl compounds (6.0 equiv.) and $N$ methylethylenediamine (3.0 equiv.)

(n)

${ }^{\mathrm{a}}$ In refluxing xylene (yields in PhMe at reflux were 17 (25\%), 18 (35\%), 19 (15\%)).

${ }^{\mathrm{b}} \mathrm{In} \mathrm{PhMe}$ at reflux.

${ }^{c}$ Using 2 equiv. of aldehyde and 1 equiv. of diamine. 
Finally, we went on to extend the TIE procedure to the one-pot preparation of pyridazines 20, 22 and 24 from tetrazines $\mathbf{1 6}, \mathbf{2 1}^{7}$ and $\mathbf{2 3}^{8}$ and phenylacetaldehyde (Table 2, entries iv-vi). In these examples, the reactions were complete in 3-5 minutes on being heated in toluene. In the case of tetrazine 21 (entry v), pyridazine 22 was obtained with complete regioselectivity (as indicated by ${ }^{1} \mathrm{H}$ NMR spectroscopy $[\delta 8.00 \mathrm{ppm}(1 \mathrm{H}, \mathrm{d}, J=2.0 \mathrm{~Hz})$ and $9.42 \mathrm{ppm}(1 \mathrm{H}, \mathrm{d}, J=$ $2.0 \mathrm{~Hz})]^{10}$

In summary, we have successfully extended the TIE methodology to prepare di-, tri- and tetra-substituted pyridazines, some annelated, from the corresponding 1,2,4,5-tetrazines in a onepot process. This procedure does not require the use of pre-formed enamines, or a separate aromatisation step, and in many examples gives almost quantitative yields of the pyridazine products.

\section{Experimental Section}

General Procedures. Tetrazines $\mathbf{2 1}^{7}$ and $\mathbf{2 3}^{8}$ were prepared according to literature procedures. All other reagents and solvents were of commercial grade. NMR spectra were recorded on Jeol EX270 or Jeol ECX400 instruments and were recorded in $\mathrm{CDCl}_{3}$. Melting points were determined on a Gallenkamp melting point apparatus.

\section{General experimental procedure}

To a solution of tetrazine ( 1 equiv.) in toluene or xylene (see Tables, $2 \mathrm{~mL}$ ) was added the carbonyl compound ( 6 equiv.) and $N$-methylethylenediamine (3 equiv.). The mixtures were heated at reflux for the specified time then allowed to cool and concentrated in vacuo. Pyridazines 11-15, 22 and 24 were purified by flash chromatography on silica (dichloromethaneethyl acetate, 9:1), whereas pyridazines 17-20 were purified by flash chromatography on alumina (deactivated with $6 \% \mathrm{H}_{2} \mathrm{O}$ w/w) (dichloromethane-ethyl acetate, 8:2 for 17-19 and 1:1 for 20).

5,6,7,8-Tetrahydro-1,4-diphenylphthalazine (11). After $13 \mathrm{~h}$ at reflux using the general procedure, 3,6-diphenyl-1,2,4,5-tetrazine 9 (50 mg, $0.21 \mathrm{mmol})$, cyclohexanone $(133 \mu \mathrm{L}, 1.28$ mmol) and $N$-methylethylenediamine $(56 \mu \mathrm{L}, 0.64 \mathrm{mmol})$ gave the title compound 11 (51 mg, $85 \%$ ) as a white solid, m.p. $172-174{ }^{\circ} \mathrm{C}$ (Lit. ${ }^{5 \mathrm{~h}}$ m.p. $172-174{ }^{\circ} \mathrm{C}$ ) displaying consistent spectroscopic data.

6,7-Dihydro-1,4-diphenyl-5H-cyclopenta[d]pyridazine (12). After $1.5 \mathrm{~h}$ at reflux using the general procedure, 3,6-diphenyl-1,2,4,5-tetrazine 9 (50 mg, $0.21 \mathrm{mmol})$, cyclopentanone $(113 \mu 1$, $1.28 \mathrm{mmol}$ ) and $N$-methylethylenediamine ( $56 \mu \mathrm{L}, 0.64 \mathrm{mmol})$ gave the title compound 12 (53 $\mathrm{mg}, 93 \%$ ) as a white solid, m.p: $160-161{ }^{\circ} \mathrm{C}$ (Lit. ${ }^{5 \mathrm{~h}}$ m.p. $161-163{ }^{\circ} \mathrm{C}$ ) displaying consistent spectroscopic data.

6,7,8,9-Tetrahydro-1,4-diphenyl-5H-cyclohepta[d]pyridazine (13). After $1.5 \mathrm{~h}$ at reflux using the general procedure, 3,6-diphenyl-1,2,4,5-tetrazine 9 (50 mg, $0.21 \mathrm{mmol}$ ), cycloheptanone (151 $\mu \mathrm{L}, 1.28 \mathrm{mmol})$ and $N$-methylethylenediamine $(56 \mu \mathrm{L}, 0.64 \mathrm{mmol})$ gave the title compound 13 
(61 mg, 97\%) as a white solid, m.p. $152-155{ }^{\circ} \mathrm{C}$ (Lit. ${ }^{5 \mathrm{~h}}$ m.p. $152-154{ }^{\circ} \mathrm{C}$ ) displaying consistent spectroscopic data.

$\mathbf{5 , 6 , 7 , 8 , 9 , 1 0 - H e x a h y d r o - 1 , 4 - d i p h e n y l - c y c l o o c t a}[d]$ pyridazine (14). After $12 \mathrm{~h}$ at reflux using the general procedure, 3,6-diphenyl-1,2,4,5-tetrazine 9 (50 $\mathrm{mg}, 0.21 \mathrm{mmol})$, cyclooctanone $(168 \mu \mathrm{L}, 1.28 \mathrm{mmol})$ and $N$-methylethylenediamine $(56 \mu \mathrm{L}, 0.64 \mathrm{mmol})$ gave the title compound 14 (59 mg, 89\%) as a white solid, m.p. $163-165^{\circ} \mathrm{C}$ (Lit. ${ }^{5 \mathrm{~h}} \mathrm{~m} . \mathrm{p} .163-165^{\circ} \mathrm{C}$ ) displaying consistent spectroscopic data.

1,4-Diphenyl[1]benzofuro[2,3-d]pyridazine (15). After $2 \mathrm{~h}$ at reflux using the general procedure, 3,6-diphenyl-1,2,4,5-tetrazine 9 (30 mg, $0.13 \mathrm{mmol})$, 3-coumaranone (104 mg, 0.78 $\mathrm{mmol})$ and $N$-methylethylenediamine $(49 \mu \mathrm{L}, 0.57 \mathrm{mmol}$ ) gave the title compound 15 (40 $\mathrm{mg}$, $95 \%$ ) as a white solid, m.p. $157-158{ }^{\circ} \mathrm{C}$ (Lit. ${ }^{5 \mathrm{c}}$ m.p. $157-158{ }^{\circ} \mathrm{C}$ ) displaying consistent spectroscopic data.

5,6,7,8-Tetrahydro-1,4-di-(2-pyridyl)phthalazine (17). After $1 \mathrm{~h}$ at reflux using the general procedure, 3,6-di-2-pyridyl-1,2,4,5-tetrazine $16(50 \mathrm{mg}, 0.21 \mathrm{mmol})$, cyclohexanone (133 $\mu \mathrm{L}$, $1.28 \mathrm{mmol})$ and $N$-methylethylenediamine $(56 \mu \mathrm{L}, 0.64 \mathrm{mmol})$ gave the title compound 17 (25 $\mathrm{mg}, 41 \%$ ) as a sticky yellow film with spectroscopic data in accord with those published. ${ }^{5 \mathrm{~h}}$

6,7,8,9-Tetrahydro-1,4-di-(2-pyridyl)-5 $H$-cyclohepta[d]pyridazine (18). After $2 \mathrm{~h}$ at reflux using the general procedure, 3,6-di-2-pyridyl-1,2,4,5-tetrazine 16 (50 mg, $0.21 \mathrm{mmol}$ ), cycloheptanone $(151 \mu \mathrm{L}, 1.28 \mathrm{mmol})$ and $N$-methylethylenediamine $(56 \mu \mathrm{L}, 0.64 \mathrm{mmol})$ gave the title compound 18 (45 mg, 71\%) as a white solid, m.p. $130-131{ }^{\circ} \mathrm{C}$ (Lit. ${ }^{5 \mathrm{~h}}$ m.p. $129-130{ }^{\circ} \mathrm{C}$ ) displaying consistent spectroscopic data.

5,6,7,8,9,10-Hexahydro-1,4-(di-2-pyridyl)cycloocta[d]pyridazine (19). After $1 \mathrm{~h}$ at reflux using the general procedure, 3,6-di-2-pyridyl-1,2,4,5-tetrazine 16 (50 $\mathrm{mg}, 0.21 \mathrm{mmol}$ ), cyclooctanone $(168 \mu \mathrm{L}, 1.28 \mathrm{mmol})$ and $N$-methylethylenediamine $(56 \mu \mathrm{L}, 0.64 \mathrm{mmol})$ gave the title compound 19 (20 mg, 30\%) as a white solid, m.p. $161-163{ }^{\circ} \mathrm{C}$ (Lit. ${ }^{5 \mathrm{~h}}$ m.p. $161-163{ }^{\circ} \mathrm{C}$ ) displaying consistent spectroscopic data.

4-Phenyl-3,6-di-(2-pyridyl)pyridazine (20). After $5 \mathrm{~min}$ at reflux using the general procedure, 3,6-di-2-pyridyl-1,2,4,5-tetrazine 16 (30 mg, $0.13 \mathrm{mmol})$, phenylacetaldehyde (89 $\mu \mathrm{L}, 0.76$ $\mathrm{mmol})$ and $N$-methylethylenediamine $(33 \mu \mathrm{L}, 0.38 \mathrm{mmol})$ gave the title compound 20 (35 $\mathrm{mg}$, 90\%) as light yellow solid, m.p. $176-178{ }^{\circ} \mathrm{C}$ (Lit. ${ }^{9}$ m.p: $177.5-178.5{ }^{\circ} \mathrm{C}$ ) displaying consistent spectroscopic data.

3,5-Diphenylpyridazine (22). After $3 \mathrm{~min}$ at reflux using the general procedure, 3-phenyl1,2,4,5-tetrazine 21 (30 mg, $0.19 \mathrm{mmol})$, phenylacetaldehyde $(133 \mu \mathrm{L}, 1.14 \mathrm{mmol}$ ) and $N$ methylethylenediamine ( $33 \mu \mathrm{L}, 0.38 \mathrm{mmol})$ gave the title compound $22(38 \mathrm{mg}, 86 \%)$ as a light yellow solid, m.p. $136-139{ }^{\circ} \mathrm{C}$ (Lit. ${ }^{10}$ m.p: $137{ }^{\circ} \mathrm{C}$ ) displaying consistent spectroscopic data.

Dimethyl 4-phenylpyridazine-3,6-dicarboxylate (24). After $5 \mathrm{~min}$ at reflux using the general procedure, dimethyl 1,2,4,5-tetrazine-3,6-dicarboxylate $23 \quad(30 \quad \mathrm{mg}, \quad 0.15 \mathrm{mmol})$, phenylacetaldehyde $(35 \mu \mathrm{L}, 0.30 \mathrm{mmol})$ and $N$-methylethylenediamine $(13 \mu \mathrm{L}, 0.15 \mathrm{mmol})$ gave the title compound $\mathbf{2 5}$ (33 $\mathrm{mg}, 80 \%$ ) as a yellow oil with spectroscopic data in accord with those published. $^{5 \mathrm{f}}$ [N.B. a 58\% yield was obtained using the standard 1:6:3 ratio of reactants due to 
purification problems; the use of a 1:2:1 ratio of reactants was successful due to the rapid rate of reaction].

\section{Acknowledgements}

We are grateful to the EPSRC for postgraduate (P.H.G.) and postdoctoral (S.A.R.) funding.

\section{References}

1. For reviews covering the cycloaddition reactions of heterocyclic azadienes see: (a) Boger, D. L. Tetrahedron 1983, 39, 2869. (b) Boger, D. L. Chem. Rev. 1986, 86, 781. (c) Boger, D. L.; Weinreb, S. N. Hetero Diels-Alder Methodology in Organic Synthesis; Academic Press: London, 1987; Chapter 10, pp 300-358.

2. (a) Boger, D. L.; Panek, J. S. J. Org. Chem. 1981, 46, 2179. (b) Boger, D. L.; Panek, J. S.; Meier, M. M. J. Org. Chem. 1982, 47, 895.

3. (a) Dittmar, W.; Sauer, J.; Steigel, A. Tetrahedron Lett. 1969, 10, 5171. (b) Taylor, E. C.; Macor, J. E. J. Org. Chem. 1987, 52, 4280. (c) Chenard, B. L.; Ronau, R. T.; Schulte, G. K. J. Org. Chem. 1988, 53, 5175.

4. (a) Raw, S. A.; Taylor, R. J. K. Chem. Commun. 2004, 508. (b) Sainz, Y. F.; Raw, S. A.; Taylor, R. J. K. J. Org. Chem. 2005, 70, 10086.

5. (a) Carboni, R. A.; Lindsey, R. V., Jr. J. Am. Chem. Soc. 1959, 81, 4342. (b) Sauer, J. ; Mielert, A.; Lang, D.; Peter, D. Chem. Ber. 1965, 98, 1435. (c) Reinhoudt, D. N.; Kouwenhoven, C. G. Recl. Trav. Chim. Pays-Bas. 1974, 93, 321. (d) Burg, B.; Dittmar, W.; Reim, H. ; Steigel, A.; Sauer, J. Tetrahedron Lett. 1975, 16, 2897. (e) Haddadin, M. J.; Firsan, S. J.; Nader, B. S. J. Org. Chem. 1979, 44, 629. (f) Boger, D. L.; Coleman, R. S.; Panek, J. S.; Yohannes, D. J. Org. Chem. 1984, 49, 4405. (g) Boger, D. L.; Panek, J. S. J. Am. Chem. Soc. 1985, 107, 5745. (h) Atfah, M. A. J. Heterocyclic Chem. 1989, 26, 717. (i) Meier, A.; Sauer, J. Tetrahedron. Lett. 1990, 31, 6855. (j) Boger, D. L.; Baldino, C. M. J. Am. Chem. Soc. 1993, 115, 11418. (k) For a recent example see: Helm, M. D.; Moore, J. E.; Plant, A.; Harrity, J. P. A. Angew. Chem. Int. Ed. 2005, 44, 3889.

6. The reaction between tetrazine $\mathbf{9}$ and cycloheptanone to give pyridazine $\mathbf{1 3}$ (Table 1, entry iii) was also carried out using morpholine in refluxing toluene and a yield of $80 \%(5 \mathrm{~h})$ was obtained. With the preformed enamine the yield was almost quantitative (but was only reported $^{5 \mathrm{~h}}$ to be $42 \%$ ). These results indicate that the yields in Aftah's publication (ref. 5h) may all be capable of improvement when carried out as one-pot processes (although the TIE procedure is still the preferred method).

7. Birkofer, L.; Hänsel, E.; Steigel, A. Chem. Ber. 1982, 115, 2574. 
8. Boger, D. L.; Coleman, R. S.; Panek, J. S.; Huber, F. X.; Sauer, J. J. Org. Chem. 1985, 50, 5377.

9. Butte, W. A.; Cage, F. H. J. Org. Chem. 1961, 26, 4690.

10. Sauer, J.; Heldmann, D. K. Tetrahedron 1998, 54, 4297. 